\title{
Adolescência e ritos de passagem: A partir de uma perspectiva do Ensino Confirmatório e Confirmação
}

\author{
Adolescence and rites of passage: \\ from a perspective of Confirmatory Teaching and Confirmation
}

\author{
Gisela I. W. Streck* \\ Ivan Kiper Malacarne ${ }^{* *}$
}

\begin{abstract}
Resumo
O artigo apresenta uma reflexão sobre os ritos de passagem em uma comunidade religiosa, mais especificamente numa comunidade urbana da Igreja Evangélica de Confissão Luterana no Brasil (IECLB) e quer ver em que medida estes ritos podem auxiliar adolescentes a fazerem a transição da infância para a vida adulta. A compreensão dos ritos de passagem como ritos de separação, de margem e de agregação será o referencial para refletir as possibilidades de adolescentes serem acompanhados/as e orientados/as nesta "travessia", também em comunidades religiosas, partindo de um estudo de caso numa comunidade de denominação luterana em um centro urbano. Nos dias de hoje - qual é o lugar dos ritos? Qual a importância que se dá aos ritos de passagem, mais especificamente ao Ensino Confirmatório e Confirmação em comunidades luteranas da IECLB? Estes ritos ainda são valorizados pela família e pela comunidade? $\mathrm{Na}$ realidade de hoje os ritos de passagem tradicionalmente oferecidos para o público adolescente em comunidades religiosas ainda fazem sentido? Em que medida famílias e lideranças comunitárias (presbitério, ministros e ministras) têm noção do significado que estes ritos de passagem podem ter na vida de adolescentes?
\end{abstract}

Palavras-chave

Adolescentes. Ritos de passagem. Religiosidade.

\begin{abstract}
The article presents a reflection on the rites of passage in a religious community, more specifically in an urban community of the Evangelical Lutheran Confession Church in Brazil (IECLB) and wants to see to what extent these rites can help adolescents make the transition from childhood
\end{abstract}

[Texto recebido em dezembro de 2017 e aceito em fevereiro de 2018, com base na avaliação cega por pares realizada por pareceristas ad hoc]

* Doutora em Teologia. Docente na Faculdades EST, São Leopoldo, RS, Brasil. E-mail: giselastreck@gmail.com

** Bacharelando em Teologia da Faculdades EST, São Leopoldo, RS, Brasil. E-mail: kipermalacarne@gmail.com 


\begin{abstract}
to adulthood. The understanding of rites of passage as rites of separation, margin and aggregation will be the referential to reflect the possibilities of adolescents being accompanied and oriented in this "crossing", also in religious communities, starting from a case study in a Lutheran denomination community in an urban center. In the present day - what is the place of the rites? How important is it to rites of passage, more specifically to Confirmatory Teaching and Confirmation in Lutheran communities of the IECLB? Are these rites still valued by family and community? In today's reality do the rites of passage traditionally offered to adolescent audiences in religious communities still make sense? To what extent do families and community leaders (presbytery, ministers) understand the significance of these rites of passage in the life of adolescents?
\end{abstract}

\title{
Keywords
}

Adolescents, Rites of passage, Religiosity.

\section{Introdução}

O presente artigo é resultado de pesquisa bibliográfica e pesquisa social sobre o caráter do Ensino Confirmatório e Confirmação como rito de passagem em comunidades da Igreja Evangélica de Confissão Luterana no Brasil (IECLB). A análise questiona em que medida estes espaços e ritos podem auxiliar adolescentes a fazerem a transição da infância para a vida adulta. A compreensão dos ritos de passagem como ritos de separação, de margem e de agregação é o referencial para indicar as possibilidades de adolescentes serem acompanhados/as e orientados/as nesta "travessia" da infância para a vida adulta. A pesquisa social pode ser definida metodologicamente com um estudo de caso e foi realizada por meio de três questionários diferentes, sendo um para adolescentes, outro para familiares e outro ainda para as lideranças da comunidade.

A pesquisa social foi realizada em uma comunidade da IECLB situada num contexto urbano no Estado do Rio Grande do Sul. Esta escolha se deve ao fato de a pesquisa estar fundamentada sob a hipótese de que, nas comunidades situadas em centros mais urbanos, há um menor comprometimento em relação à tradição, principalmente da família, de enviar seus filhos e suas filhas adolescentes ao Ensino Confirmatório e Confirmação. Aqui entram também questões relacionadas com uma crescente religiosidade desinstitucionalizada, um maior descomprometimento com a tradição e com a adesão a uma comunidade religiosa. A coleta de dados foi realizada através de questionários com perguntas fechadas e abertas - um específico para quatorze adolescentes (nove meninas e cinco meninos); outro para um familiar de cada adolescente; e outro para oito lideranças (diretoria da comunidade - seis pessoas - ministro e ministra). ${ }^{1}$

\footnotetext{
1 A pesquisa social foi aprovada pelo Comitê de Ética em Pesquisa da Faculdades EST e todas as pessoas que participaram assinaram o Termo de Consentimento Livre e Esclarecido. No caso de adolescentes, o TCLE foi assinado por uma pessoa responsável.
} 


\section{Ritos de passagem e adolescência}

A adolescência é uma etapa na vida do ser humano que se situa entre a infância e a idade adulta. Nas sociedades ocidentais, ela é uma etapa preparatória para a adultez e de espera para a integração na sociedade adulta. Contardo Calligaris ${ }^{2}$ afirma que o problema para a pessoa adolescente é a duração desta fase, pois a sociedade impõe uma moratória sem prazo de duração. Como se sai da adolescência? Para esta pergunta não há uma resposta precisa.

Françoise Dolto ${ }^{3}$ afirma que adolescentes, entregues a si mesmos/as, não são mais levados/as em conjunto e solidariamente de uma margem para a outra, mas eles/as mesmos/as devem fazer a "travessia", individualmente, o que pode gerar angústia, medo e solidão.

O ser humano não vive sem ritos; é uma necessidade e faz parte da essência humana ritualizar sua vida e seu cotidiano. $\mathrm{O}$ rito assinala a passagem de uma situação a outra e van Gennep afirma:

É o próprio fato de viver que exige as passagens sucessivas de uma sociedade especial a outra e de uma situação social a outra, de tal modo que a vida individual consiste em uma sucessão de etapas, tendo por término e começo conjuntos da mesma natureza, a saber, nascimento, puberdade social, casamento, paternidade, progressão de classe, especialização de ocupação, morte. ${ }^{4}$

Nas comunidades da IECLB, o Ensino Confirmatório é um período que enfatiza a educação dos principais temas inerentes a fé cristã, segundo a perspectiva luterana. $\mathrm{O}$ processo culmina com uma celebração eucarística denominada de Confirmação. Neste momento, o e a adolescente confessam, publicamente, sua fé, além disso, são inseridos no mundo adulto comunitário. A dinâmica do Ensino Confirmatório e da Confirmação está relacionada com o Batismo e também compreende o principal momento de formação na IECLB. $^{5}$

O constituição do Ensino Confirmatório/Confirmação (semelhante ao processo da Catequese na Igreja Católica Apostólica Romana) permitiu que este se consolidasse no período entre a infância e o mundo adulto. Tornou-se, assim, um rito de passagem entre os dois momentos do desenvolvimento humano. Com instalação da progressiva indefinição do término da adolescência e consequente ingresso no mundo adulto, o rito começou a

\footnotetext{
CALLIGARIS, Contardo. A adolescência. 2.ed. São Paulo: Publifolha, 2009.

DOLTO, Françoise. A causa dos adolescentes. Aparecida: Idéias \& Letras, 2004.

GENNEP, Arnold van. Os ritos de passagem. Petrópolis: Vozes, 1977. p. 26-27.

WACHS, Manfredo Carlos. Confirmação na IECLB: contribuições para um método. São Leopoldo: Escola Superior de Teologia, 1995.
} 
apresentar problemas. Especialmente o momento de agregação na comunidade expõe um déficit no reconhecimento de uma nova posição do e da adolescente no seio comunitário. ${ }^{6}$

Para analisar e entender os dados obtidos é necessário fazer uma releitura da realidade de hoje e perceber as mudanças que esta traz. A primeira refere-se à influência da igreja na vida das pessoas participantes das comunidades. No período da prémodernidade, a religião determinava toda a vida da sociedade. Temas como ordem social, costumes e moral eram regulados pela ordem eclesiástica. ${ }^{7}$ Com isso, os ritos de passagem estavam definidos, pois sinalizavam, de forma determinada, a transição de um momento para outro. Em comunidades luteranas da região rural, essas características se mantêm com certa semelhança ao período pré-moderno. As comunidades são constituídas e unidas através da igreja. Sendo assim, os ritos religiosos são determinantes para a vida das pessoas, especialmente o rito de passagem do Ensino Confirmatório/Confirmação.

Todavia, nas comunidades urbanas percebe-se maior influência da modernidade em questões de organização da vida social. Nelas, a igreja torna-se uma dentre muitas instituições que organizam a vida humana. As atividades da escola ou do trabalho, por exemplo, não estão subordinadas à autoridade da igreja. Sendo assim, novas variantes interferem no processo de transição da adolescência para o mundo adulto, levando, segundo Calligaris, a uma moratória social. ${ }^{8}$ Nesta perspectiva, o rito do Ensino Confirmatório/Confirmação não insere adolescentes no mundo adulto, visto que não resolve todos os conflitos e variantes pertinentes à adolescência. Por exemplo, destas variantes pode-se destacar que o rito não tem o objetivo de conceder ou ter como prerrogativa a aquisição de independência financeira de adolescentes, um dos requisitos necessários para se inserir no mundo adulto.

Outro aspecto a ser considerado é a relação do fim do período do Ensino Confirmatório/Confirmação com a finalização da educação básica. Os imigrantes luteranos e as imigrantes luteranas, que chegaram ao Brasil a partir de 1824, se estabelecerem em torno da igreja e da escola. Os dois ambientes estavam um ao lado do outro, por vezes, compartilhando o mesmo espaço físico. Por isso, pastores foram professores. ${ }^{9}$ Além disso, a Confirmação celebrava o término da educação religiosa oferecida nas comunidades da IECLB, que coincidia com a finalização do processo educacional de alfabetização na escola. Era um momento de conclusão de uma etapa evidentemente demarcada. Ademais, também corrobora para a afirmação discutida acima: a igreja era a máxima e principal influência na vida das pessoas.

\footnotetext{
WACHS, 1995.

DREHER, Martin Norberto. História do povo luterano. São Leopoldo: Sinodal, 2005. p. 9-13.

8 Moratória social é, para Calligaris, a própria fase da adolescência. É um período de espera imposto pela sociedade, com a justificativa de que adolescentes ainda não estão preparados e aptos para ingressarem no mundo das pessoas adultas. CALLIGARIS, , 2009, p. 15.

9 DREHER, 2005, p.52-3.
} 


\section{Ensino Confirmatório na perspectiva de adolescentes, familiares e lideranças comunitárias}

A partir dados obtidos do questionário dos e das adolescentes, de quatorze participantes, onze pessoas estão com doze anos. Neste período, elas ainda estão muito distantes de concluir a formação básica prevista pela legislação brasileira (até o Ensino Médio). Portanto, o rito do Ensino Confirmatório/Confirmação não acontece concomitante ao período de encerramento dos estudos básicos, não sendo assim um período de transição para a idade adulta.

$\mathrm{Na}$ questão quatro do mesmo questionário que perguntou sobre quem havia inscrito os/as adolescentes no Ensino Confirmatório, doze responderam que foi a família, sendo que apenas dois tiveram iniciativa própria. Meyer-Blanck e Karl Dienst afirmam que na Igreja Antiga "[...] o batismo, a eucaristia e a bênção não são vistos isoladamente, mas considerando sua função de acesso à fé individual e à religião organizada comunitariamente".$^{10}$ Portanto, o ingresso na comunidade cristã era um aceite individual para a passagem para uma outra realidade. Contudo, a análise do questionário permite verificar que não mais acontece dessa forma, mas os familiares são responsáveis por integrar filhos e filhas no Ensino Confirmatório, muitas vezes preocupados em manter certo "tradicionalismo"11 familiar.

Nas perguntas cinco, onze e sete do questionário para adolescentes, o Ensino Confirmatório e o rito da Confirmação foram incisivamente associados à educação. Esta foi relacionada com diversos temas, dentre eles: palavra de Deus, igreja, religião, fé cristã, respeito, mandamentos, doutrina e Jesus. Perguntas sobre o motivo, a importância e o significado do Ensino Confirmatório e da Confirmação foram respondidas, em grande medida, com questões relacionadas ao "aprender".

\section{Gráfico 1: Pergunta $n^{0} 5$ (adolescentes): Você sabe por que frequenta o Ensino Confirmatório?}

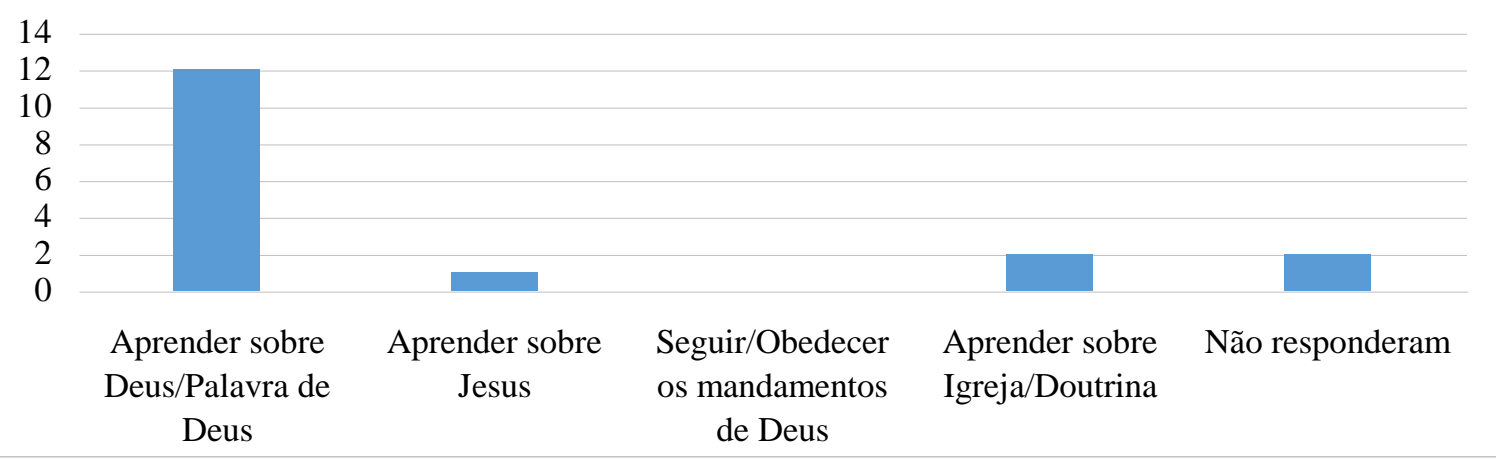

Fonte: Banco de Dados da Pesquisa, 2017.

10 MEYER-BLANCK, Michael; DIENST, Karl. A Confirmação. In: SCHMIDT-LAUBER, Hans-Christoph; MEYER-BLANCK, Michael; BIERITZ, Karl-Heinrich. Manual de ciência litúrgica: ciência litúrgica na teologia e prática da igreja. São Leopoldo: Faculdades EST/Sinodal, 2011. v. 3. p. 44.

11 Aqui, tradicionalismo é compreendido como uma forma negativa da tradição. 
Gráfico 2: Pergunta $n^{0} 7$ (adolescentes): Você considera importante frequentar o Ensino Confirmatório?

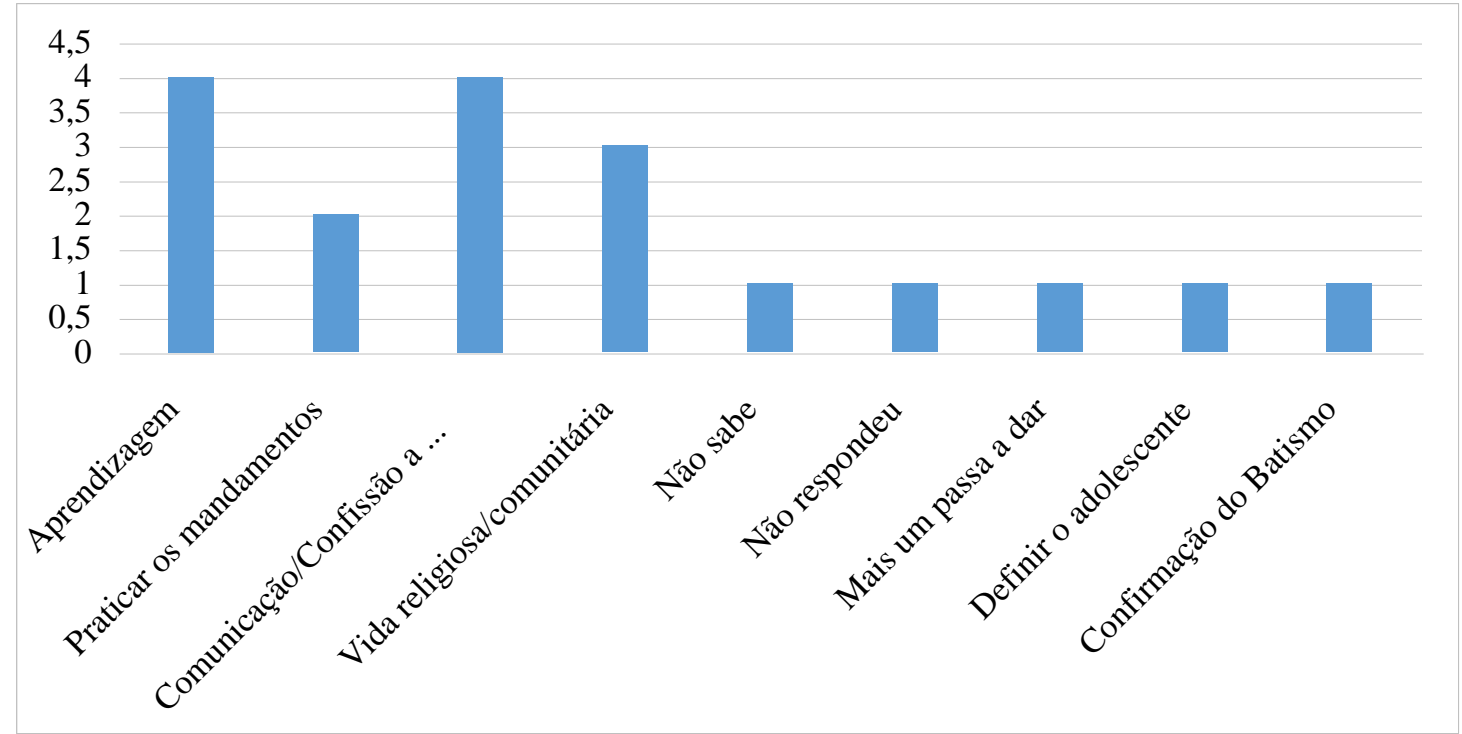

Fonte: Banco de Dados da Pesquisa, 2017.

Gráfico 3: Pergunta $n^{0} 11$ (adolescentes): O que Confirmação significa para você?

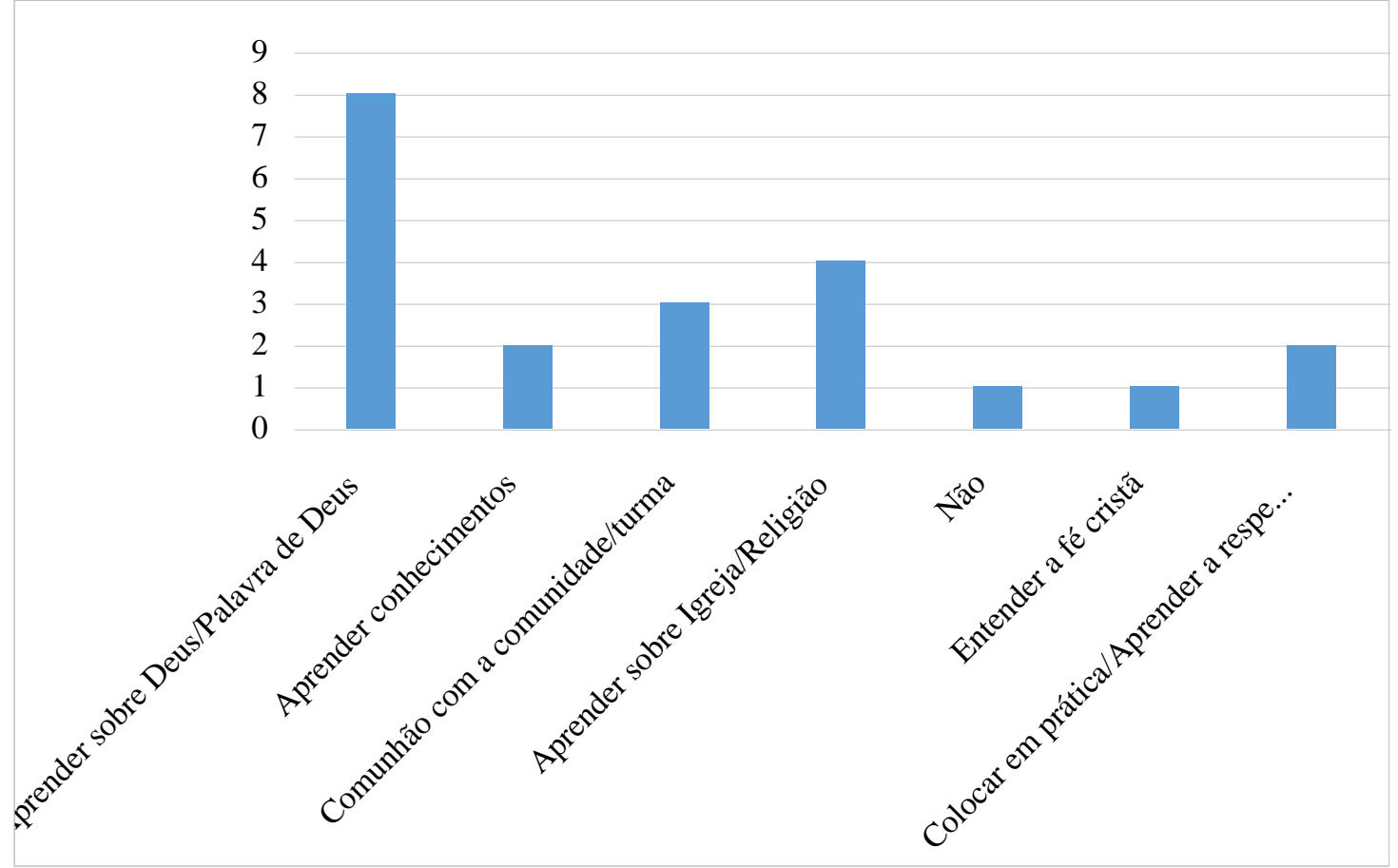

Fonte: Banco de Dados da Pesquisa, 2017.

Os questionários de familiares (perguntas quatro e cinco) e das lideranças (pergunta quatro) também corroboram as perspectivas dos e das adolescentes e as respostas enfocaram a questão da educação e do aprendizado. 


\section{Gráfico 4: Pergunta $n^{\circ} 4$ (familiares): O que significa o Ensino Confirmatório para você?}

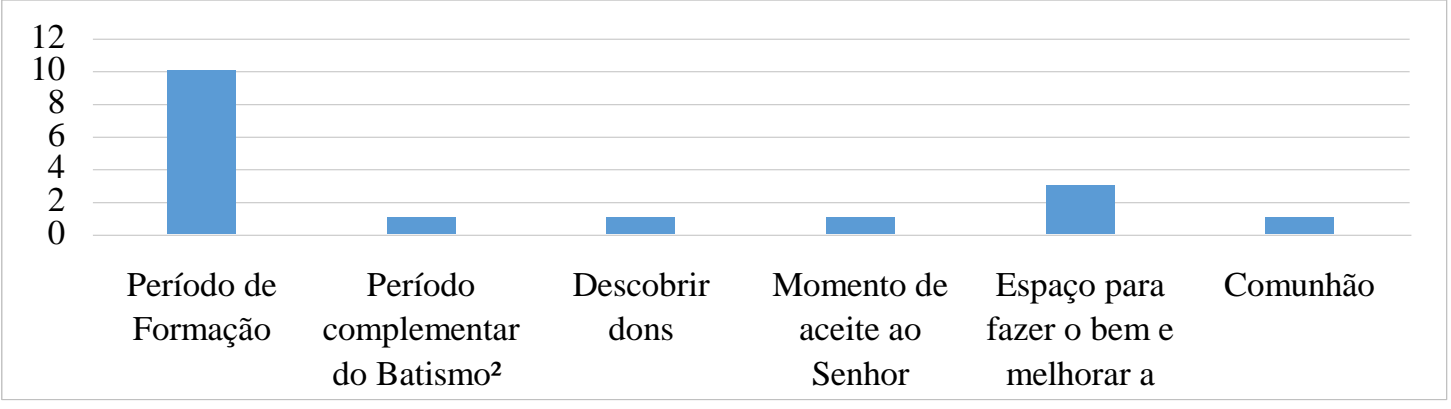

Fonte: Banco de Dados da Pesquisa, 2017.

Gráfico 5: Pergunta $n^{\circ} 5$ (familiares): Você acha importante que seu filho ou filha participe do Ensino Confirmatório?

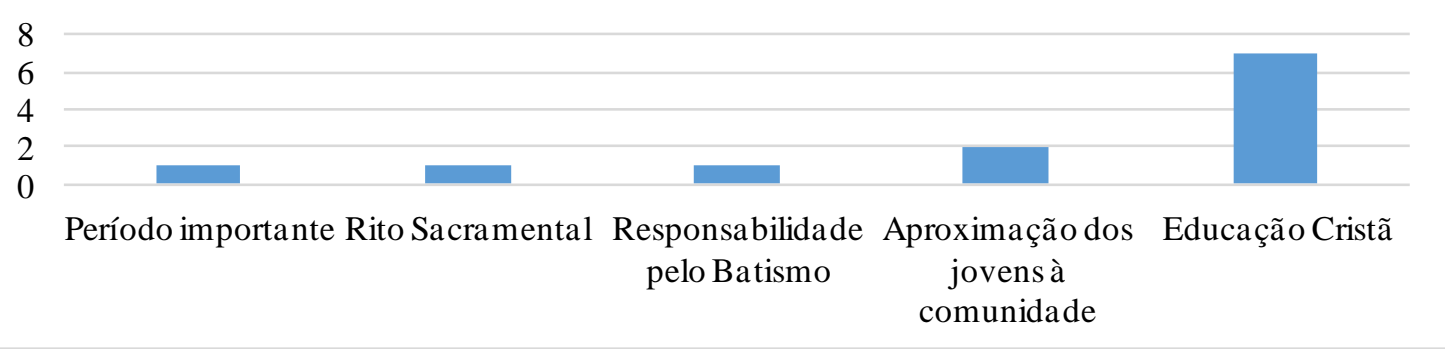

Fonte: Banco de Dados da Pesquisa, 2017.

Gráfico 6: Pergunta no 4 (lideranças) - Qual o significado do Ensino Confirmatório para você?

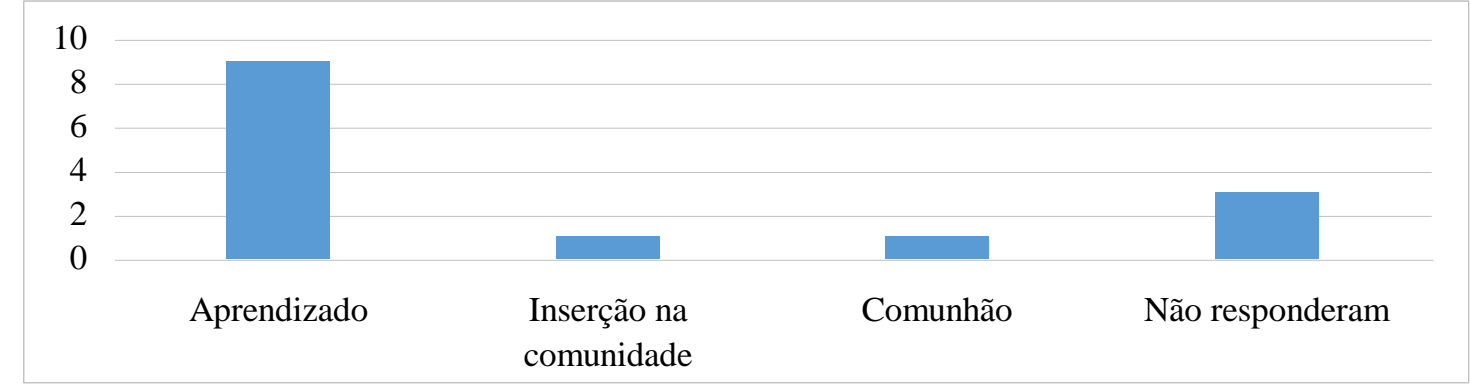

Fonte: Banco de Dados da Pesquisa, 2017.

O Ensino Confirmatório é um dos principais momentos deste processo, sendo visto por muitas pessoas como o único. Segundo Wachs, nas igrejas luteranas, o período do Ensino Confirmatório/Confirmação está muito centrado no tema da educação cristã. Isso, segundo o autor, pode fortalecer uma "compreensão de rito de passagem e de formatura ou despedida da comunidade".12 Conclui-se que a ênfase do Ensino Confirmatório na educação pode desestimular a perspectiva de um rito de passagem, motivando adolescentes a deixarem o convívio comunitário. Neste caso, o terceiro passo do rito de passagem, o da agregação, não se efetiva.

12 WACHS, 1995, p. 66. 
O processo educativo oferecido pelo Ensino Confirmatório não traz algo diferenciado em relação ao da escola. Por isso, há uma sobrecarga de atividades para adolescentes que frequentam o Ensino Confirmatório, diminuindo o interesse e a identificação com a comunidade na qual participam.

Nos primeiros cinco séculos da igreja cristã, Batismo e Ensino Confirmatório/Confirmação estiveram intrinsicamente relacionados e formavam um único momento que se consolidava em algumas etapas. ${ }^{13} \mathrm{O}$ momento era profundo e celebrava a iniciação cristã, através de intensos momentos. White descreve estes, contendo "[...] uma variedade de ações, todas elas implicando uma forte sensação de toque: unções, lavagem, imposição de mãos e selagem, o beijo (ósculo da paz), além de comer e beber". 14

Kalmbach destaca três motivos que levaram a igreja a separar a iniciação cristã em momentos distintos: “a) conversão em massa; b) generalização do batismo de crianças; c) presbíteros começaram a assumir funções sacramentais, como o batismo de crianças, reservadas anteriormente ao bispo". ${ }^{15}$ Os bispos, à medida que dispunham de mais autoridade, tornaram-se responsáveis pela unção, selagem e bênção. Isto permitiu o rompimento do rito em dois momentos distintos: o primeiro, caracterizado pelo ato batismal, era realizado por presbíteros e presbíteras da comunidade, e o segundo, composto pelas três ações acima citadas, sendo o bispo de determinada região responsável por concluir a cerimônia dias ou semanas depois.

O papa Inocêncio I, no ano de 416, possibilitou este acontecimento na igreja do Ocidente, enquanto no Oriente, o processo permaneceu integrado. ${ }^{16}$ No desenvolvimento da Idade Média, os dois momentos, batismo e confirmação (unção, selagem e bênção), foram se distanciando ainda mais. Portanto, a separação entre batismo, confirmação e primeira comunhão (primeira participação na eucaristia/santa ceia) prejudica a compreensão do valor e do significado do rito nos seus diferentes momentos. White afirma que, teologicamente, isso interfere na percepção da totalidade das ações de Deus para com a comunidade. ${ }^{17}$

$\mathrm{Na}$ pergunta seis dos e das adolescentes, ${ }^{18}$ oito pessoas afirmaram que os dois momentos, Batismo e Confirmação são presentes de Deus. Também afirmaram que a Confirmação é confirmar o Batismo, além de possibilitar a integração na vida religiosa e conduzir a uma maturidade na vida religiosa. No entanto, também é alto o número daqueles e daquelas que responderam não saber o que significa todo este processo.

13 KALMBACH, Pedro. Batismo e confirmação nos primeiros cinco séculos da Igreja Cristã: aproximações. Estudos Teológicos, São Leopoldo, v. 42, n. 3, 2002. p. 18-19; SCHMIDT-LAUBER; MEYERBLANCK; BIERITZ, 2011, p. 44.

14 WHITE, James F. Introdução ao culto cristão. 3.ed. rev. São Leopoldo: Sinodal/Faculdades EST, 2012. p. 133.

15 KALMBACH, 2011, p. 24.

16 KALMBACH, 2011, p. 24.

17 WHITE, 2012, p. 146.

18 Pergunta $n^{\circ} 6$ (adolescentes): Você sabe a relação entre o seu batismo e a confirmação? 
Portanto, não está evidente, para a maioria, que os dois momentos são, teologicamente, parte da iniciação cristã. No caminho de ressignificação do processo, White sugere que o Batismo seja renovado, visto que é de grande importância para a memória cristã. O autor sugere que celebrações de renovação aconteçam, pelo menos, uma vez no ano. ${ }^{19}$ Além disso, para obter uma educação significativa, durante o Ensino Confirmatório, é importante que ela auxilie a compreender a mística envolvida no rito.

$\mathrm{Na}$ pergunta oito dos e das adolescentes, ${ }^{20}$ seis afirmaram que familiares acompanham pouco e dois disseram que não há acompanhamento. Isto também enfraquece o significado do rito, visto que não apresenta o cuidado da família com os e as adolescentes nas atividades que desenvolvem. Isto poderá ser sintomático para outras dimensões da relação entre familiares e adolescentes como, por exemplo, a falta de acompanhamento nas atividades escolares e no desenvolvimento dos e das adolescentes nesta fase da vida. Escola e igreja, cuidado e acompanhamento familiar são muito importantes para motivar e ensinar, e para valorizar o desenvolvimento da nova identidade que está sendo constituída.

Uma iniciativa para ressignificar o rito, desde o Batismo até a Confirmação, é promover atividades que envolvam familiares e adolescentes, além de reuniões com as pessoas que assumem a tarefa de orientar o processo do Ensino Confirmatório. O intuito é possibilitar momentos de diálogo entre orientadores, orientadoras, familiares, ministros e ministras da comunidade sobre as atividades que estão sendo desenvolvidas, além de identificar como cada adolescente está acompanhando o grupo e o processo educacional.

A pergunta dez do questionário dos e das adolescentes ${ }^{21}$ mostra que a metade do grupo respondeu que não há uma relação entre os temas estudados no Ensino Confirmatório e a vida cotidiana de cada pessoa. Este aspecto é importante, pois segundo van Gennep, o processo de margem dos ritos de iniciação, neste caso o período do Ensino Confirmatório, é a parte mais relevante em relação aos processos de separação e de agregação. ${ }^{22}$

Portanto, um processo educativo que contemple uma relação de mútua aprendizagem entre as pessoas adultas da comunidade (orientador/a, presbíteros/as, ministros/as) e adolescentes, oferecendo auxílio na resolução de crises existenciais ${ }^{23}$ e orientação para o fortalecimento de uma identidade positiva é necessário para que o rito do Ensino Confirmatório e da Confirmação tenha significado, ou seja, faça sentido na vida de adolescentes e suscite um sentimento de pertencimento à comunidade.

19 WHITE, 2012, p.146.

20 Pergunta $n^{\circ} 8$ (adolescentes): Os seus familiares/responsáveis acompanham seus estudos durante o Ensino Confirmatório?

21 Pergunta 10 (adolescentes): Há ligação entre os temas estudados e o seu dia-a-dia?

22 GENNEP, 1977, p. 31.

23 MANSK, Erli. Ritos de Passagem: necessidade humana e oportunidade para a vida litúrgica da comunidade. Tear: liturgia em revista, São Leopoldo, n. 25, maio 2008. p. 3. 
A pergunta quatorze tinha como objetivo ver em que medida os e as adolescentes percebem que a comunidade oferece espaços para sua participação ou estão dispostos a se inserirem nestes lugares. As respostas apontam com maior incidência para grupos já organizados e que são tradicionais nas comunidades, como os grupos de Juventude Evangélica ou grupos de música.

Gráfico 7: Pergunta $n^{\circ} 14$ (adolescentes): Depois da Confirmação, como você pensa que será ou qual será seu lugar na sua comunidade religiosa?

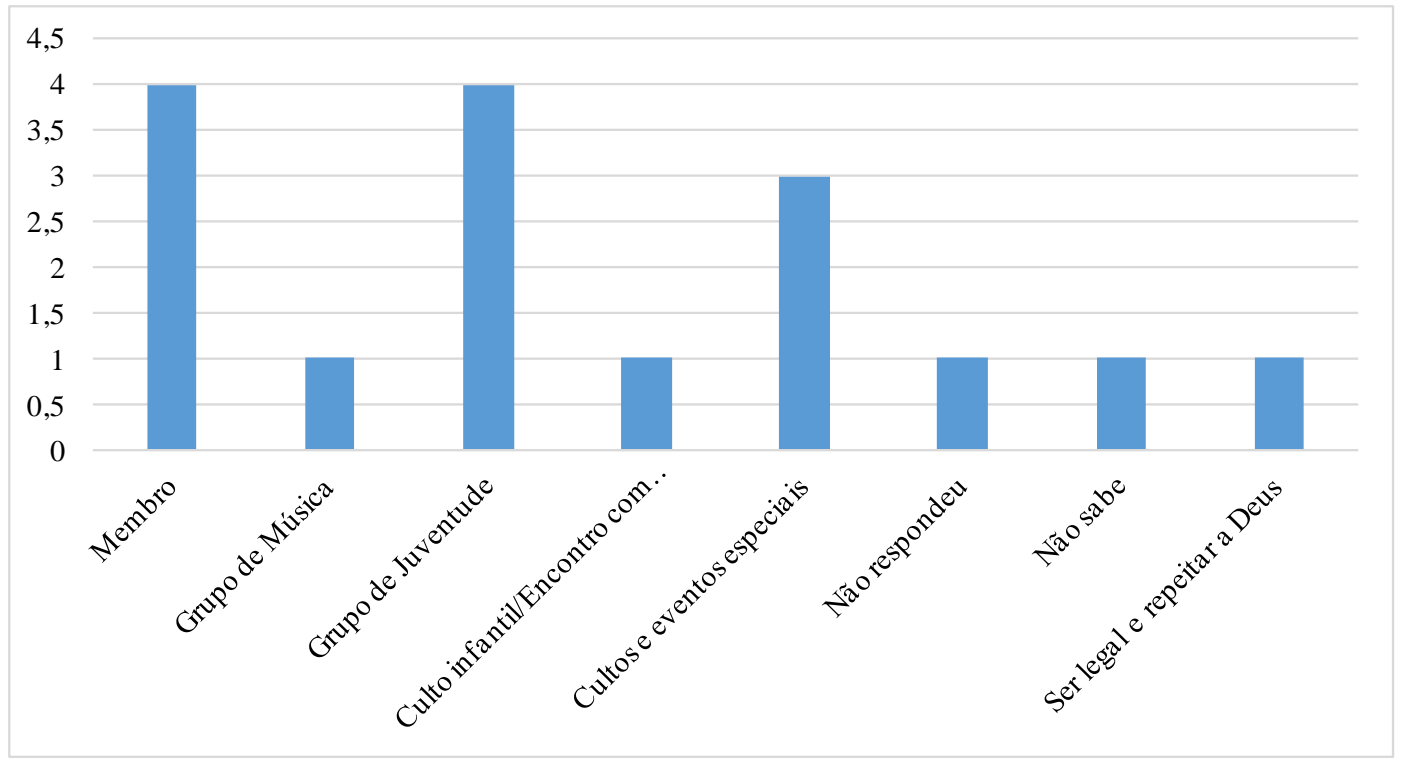

Fonte: Banco de Dados da Pesquisa, 2017.

Na pergunta nove dos questionários das lideranças e dos familiares há referência a várias atividades oferecidas que anseiam incluir adolescentes na vida comunitária, mas é destaque que também são mencionadas atividades que, normalmente, são organizadas para crianças, como Noite do Pijama, Encontro de Crianças.

Gráfico 8: Pergunta $n^{\circ} 9$ (familiares) - Quais são as atividades para os/as adolescentes e a comunidade os/as incentiva a participarem?

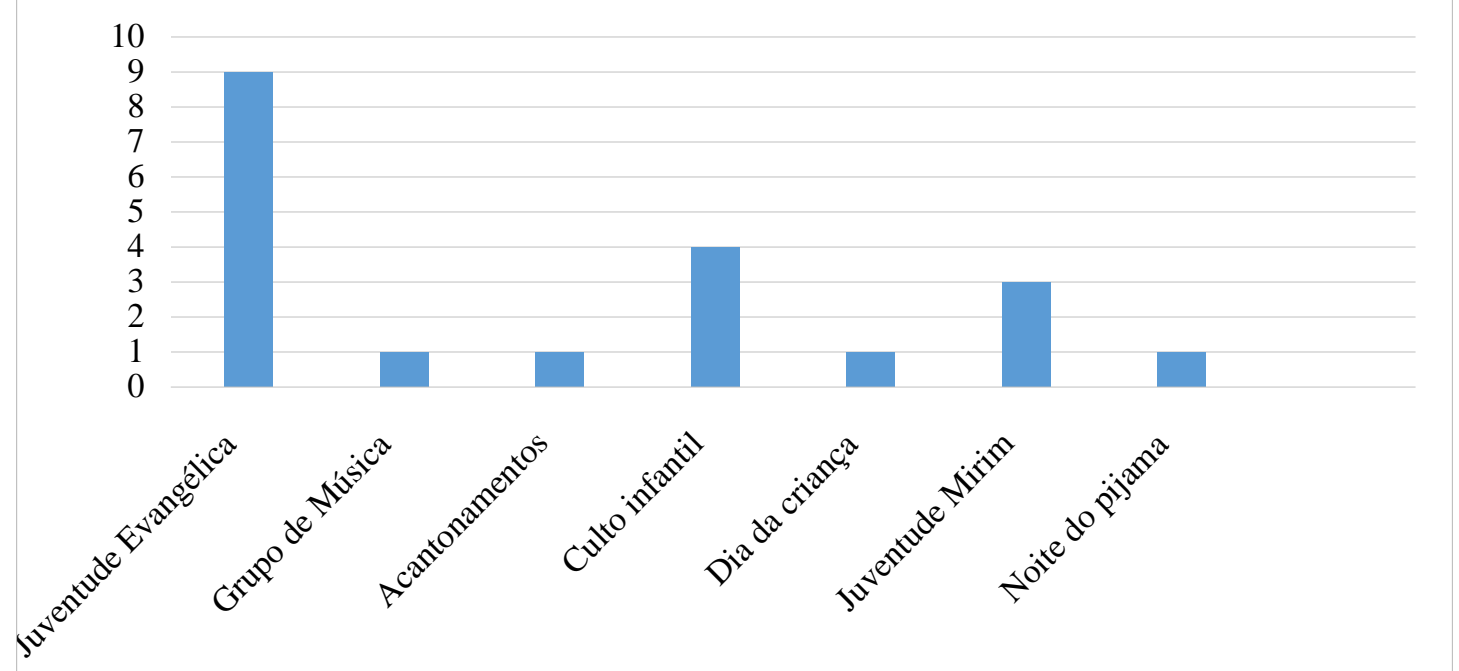

Fonte: Banco de Dados da Pesquisa, 2017. 
Gráfico 9: Pergunta $\mathbf{n}^{\circ} 9$ (lideranças): Quais são as atividades para os/as adolescentes e a comunidade os/as incentiva a participarem?

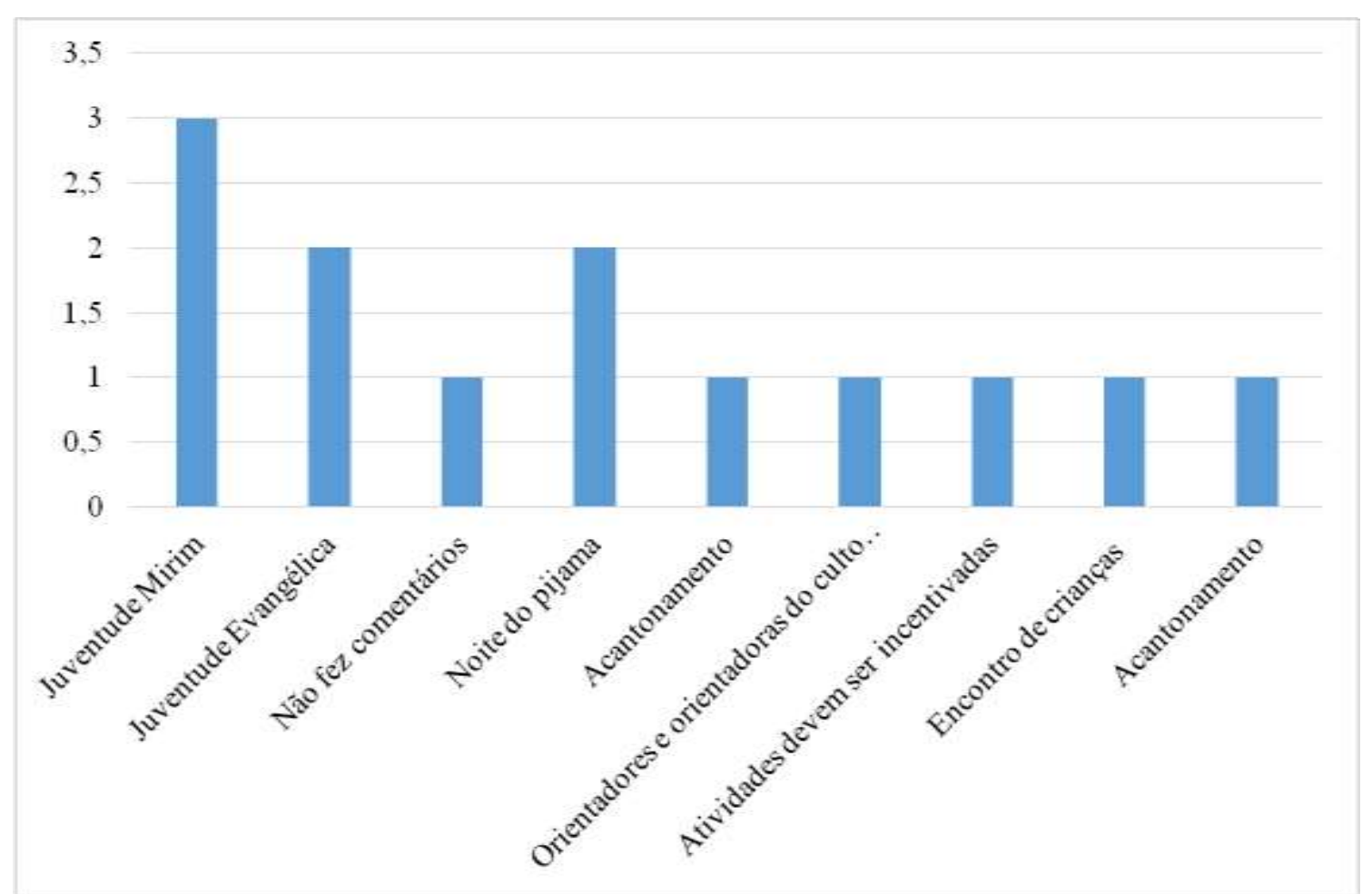

Fonte: Banco de Dados da Pesquisa, 2017.

Nesta mesma direção, na pergunta quinze ${ }^{24}$ dez adolescentes afirmaram que as pessoas adultas não mudarão a forma de tratá-los/las, ou seja, não haverá uma mudança na forma de ver os e as adolescentes depois da Confirmação. Sendo assim, não há como afirmar que o processo como um todo insere o ou a adolescente na comunidade como membro adulto.

\section{Considerações finais}

Diante do que foi exposto, conclui-se que o rito de passagem que contempla o Ensino Confirmatório e a Confirmação não insere os e as adolescentes na comunidade como membros adultos e nem os acompanha e orienta na sua busca por entender esta fase da vida e integrar-se no mundo adulto da comunidade religiosa. Algumas propostas podem ser levadas em conta, para que se possa repensar este rito de passagem, especialmente o momento do Ensino Confirmatório. Uma delas seria desenvolver uma educação holística, comunitária e dinâmica, que contemple e reflita as crises existenciais da adolescência, fortalecendo o estudo de temas relacionados ao cotidiano das pessoas adolescentes, suas dúvidas, seus medos, suas dores e suas conquistas e alegrias. Ao levar em consideração esta fase da vida e se colocar solidariamente ao lado de adolescentes para

24 Pergunta 15 (adolescentes): Depois da Confirmação, você imagina que as pessoas adultas da comunidade mudarão sua forma de trata-lo/a 
acompanhá-los/as e orientá-los/as, a comunidade religiosa reconhece este grupo como tendo as suas próprias necessidades. Assim a formação especial reservada a adolescentes no Ensino Confirmatório pode ser entendida como um rito de separação e de margem, um tempo especial em que são acompanhados/as na sua "travessia".

Uma segunda questão diz respeito à relação entre Batismo e Confirmação. Neste sentido seria importante fortalecer ritos como o Batismo e a Confirmação e para além destes, fortalecendo os vínculos comunitários e a compreensão de que há uma continuidade. Para tanto seria possível organizar uma Pastoral do Batismo, para acompanhar crianças batizadas até o início do Ensino Confirmatório, e integrar, em atividades e conversas, familiares e adolescentes. Seria importante ter clareza sobre a necessidade de oferecer experiências e rituais que vão além da Confirmação, no sentido de incorporar adolescentes à comunidade após a Confirmação, dando-lhes a certeza de que a vida na sua totalidade, nas suas diferentes fases, tem espaço na vida comunitária, desde o Batismo como crianças até o final da vida. Aqui o rito da agregação na adolescência encontra o seu significado e a sua importância.

Esta pesquisa trouxe dados de uma comunidade específica da IECLB, não contemplando todas as realidades comunitárias e toda a atual situação do Ensino Confirmatório e da Confirmação. Por isso seria importante e necessário o desenvolvimento de novas reflexões e interações entre lideranças eclesiásticas, comunidades de fé, familiares e adolescentes.

\section{Referências}

CALLIGARIS, Contardo. A adolescência. 2.ed. São Paulo: Publifolha, 2009.

DREHER, Martin Norberto. História do povo luterano. São Leopoldo: Sinodal, 2005.

GENNEP, Arnold van. Os ritos de passagem. Petrópolis: Vozes, 1977.

KALMBACH, Pedro. Batismo e confirmação nos primeiros cinco séculos da Igreja Cristã: aproximações. Estudos Teológicos, São Leopoldo, v. 42, n. 3, 2002.

MANSK, Erli. Ritos de Passagem: necessidade humana e oportunidade para a vida litúrgica da comunidade. Tear: liturgia em revista, São Leopoldo, n. 25, maio 2008.

MEYER-BLANCK, Michael; DIENST, Karl. A Confirmação. In: SCHMIDT-LAUBER, Hans-Christoph; MEYER-BLANCK, Michael; BIERITZ, Karl-Heinrich. Manual de ciência litúrgica: ciência litúrgica na teologia e prática da igreja. São Leopoldo: Faculdades EST, Sinodal, 2011. v. 3.

NOSSA fé, nossa vida. Disponível em: <http://www.luteranos.com.br/conteudo/nossa-fe-nossavida-a-confirmacao $>$. Acesso em: 23 nov. 2015. 
WACHS, Manfredo Carlos. Confirmação na IECLB: contribuições para um método. São Leopoldo: Escola Superior de Teologia, 1995.

WHITE, James F. Introdução ao culto cristão. 3.ed. rev. São Leopoldo: Sinodal/Faculdades EST, 2012. 